\title{
APRENDIZAGEM CONCEITUAL E DESENVOLVIMENTO DO PENSAMENTO: ANÁLISE DO POTENCIAL FORMATIVO DO ENSINO PROPOSTO EM UM LIVRO DIDÁTICO
}

\author{
CONCEPTUAL LEARNING AND DEVELOPMENT OF THOUGHT: \\ ANALYSIS OF THE FORMATION POTENTIAL FOR TEACHING PROPOSED IN A TEXTBOOK
}

\author{
BRUNA LORENA BACARO 1 \\ MARTA SUELI DE FARIA SFORNI²
}

\section{RESUMO}

De acordo com a Teoria Histórico-Cultural, a aprendizagem de conceitos científicos é promotora do desenvolvimento psíquico dos estudantes. Todavia, nem sempre se observa o impacto positivo dessa aprendizagem no desenvolvimento do pensamento de pessoas escolarizadas, o que gera a necessidade de refletir sobre como esses conceitos são ensinados. Neste artigo é apresentada parte de uma pesquisa que buscou analisar, de modo qualitativo, o potencial formativo presente na forma de organização do ensino de conceitos apresentada por um livro didático de Ciências dos anos iniciais do Ensino Fundamental. Mediante a análise de conteúdo, conclui-se que o ensino proposto é marcado pela definição conceitual e exemplificação, sem exigir ações que levem os estudantes a pensar conceitualmente os fenômenos. Esse modo de organização do ensino pode justificar o incipiente impacto da aprendizagem conceitual na formação dos estudantes e a necessidade de superá-lo, quando se assume o desenvolvimento do pensamento dos estudantes como finalidade da educação escolar.

Palavras-chave: Aprendizagem conceitual. Livro Didático. Teoria Histórico-Cultural.

\section{ABSTRACT}

Historical-Cultural Theory underscores that the learning of scientific concepts produces students' psychic development. However, the positive impact of this type of learning may not be detected in the development of people with a schooling background. This fact makes one discuss the manner these concepts are taught. Current paper comprises a section of a research work qualitatively analyzes the formation potential current in the organization of the teaching of concepts forwarded in a Science textbook for the first of Basic Education. Content analysis showed that teaching was characterized by a conceptual definition and exemplification, without making mandatory activities that would lead the students to think the phenomena conceptually. Such teaching organization, highly common in schools, may explain the initial impact of conceptual learning in student formation and the need to go beyond it when one is committed to students' development as the target in schooling education.

Keywords: Conceptual learning. Textbook. Historical-Cultural Theory.

\section{RESUMEN}

Según la Teoría Histórico-Cultural, el aprendizaje de conceptos científicos promueve el desarrollo psíquico de los estudiantes. Sin embargo, el impacto positivo de este aprendizaje no siempre se observa en el desarrollo del pensamiento de las personas escolarizadas, lo que genera la necesidad de reflexionar sobre cómo se enseñan estos conceptos. En este artículo se presenta parte de una investigación que busca analizar, de manera cualitativa, el potencial formativo presente

1 Mestre em Educação. Professora da Educação Básica. E-mail: bruna_bacaro@hotmail.com. Orcid: https://orcid.org/0000-0003-2764-444X. 2 Doutora em Educação. Professora do Programa de Pós-Graduação em Educação da Universidade Estadual de Maringá-PR. E-mail: martasforni@ uol.com.br. Orcid: https://orcid.org/0000-0002-9614-2075 
en la forma de organizar la enseñanza de conceptos que presenta un libro didáctico de ciencias desde los primeros años de la escuela primaria. A través del análisis de contenido, se concluye que la enseñanza propuesta está marcada por la definición y ejemplificación conceptual, sin requerir acciones que lleven a los estudiantes a pensar conceptualmente sobre los fenómenos. Esta forma de organización de la enseñanza puede justificar el incipiente impacto del aprendizaje conceptual en la formación de los estudiantes y la necesidad de superarlo, al asumir el desarrollo del pensamiento de los estudiantes como finalidad de la educación escolar.

Palabras-clave: Aprendizaje conceptual. Libro didáctico. Teoría histórico-cultural.

\section{INTRODUÇÃO}

A aprendizagem de conceitos científicos é condição fundamental para 0 desenvolvimento psíquico de crianças e adolescentes, de modo especial, por propiciar a formação do pensamento teórico e, com ele, uma visão de mundo mais profunda e sistêmica. Os fenômenos podem ser melhor compreendidos pela mediação dos conhecimentos científicos apropriados durante a escolarização.

No entanto, em argumentos e comportamentos apresentados por muitas pessoas escolarizadas nem sempre se percebe uma diferença significativa na visão de mundo que revelam acerca dos fenômenos. Como exemplo dessa situação, basta observar as argumentações em torno de assuntos que apesar de não serem novos no campo da ciência, recentemente, têm ocupado a pauta das discussões de modo intenso, como: vacinação, imunização, equilibrio ambiental, desmatamento, dentre outros.

É instigador o fato de, em muitas situações, não se perceber uma forma teórica de pensar os fenômenos. Os conceitos científicos que fazem parte do currículo da Educação Básica, não são orientadores dos argumentos apresentados por muitas pessoas, o que revela que a escola tem tido pouco impacto no desenvolvimento do pensamento de uma parcela da população.

Enfim, por um lado há uma proposição afirmativa sobre o poder da aprendizagem conceitual no desenvolvimento dos estudantes, por outro há uma realidade que parece negar tal proposição. Como compreender tal contradição? As palavras de Davidov (1988) indica um caminho para a busca de respostas.

0 problema do ensino e a educação que impulsionam o desenvolvimento estão estreitamente ligados à fundamentação lógico-psicológica da estruturação das disciplinas escolares. 0 conteúdo destas e os meios para empregá-los no processo didático-educativo determinam essencialmente o tipo de consciência e de pensamento que se forma nos escolares durante a assimilação dos correspondentes conhecimentos, atitudes e hábitos. Por isso, as questỗes referentes à estruturação das disciplinas escolares não têm uma importância estreita, mas ampla, desde 0 ponto de vista das particularidades do desenvolvimento psíquico dos escolares (DAVIDOV, 1988, p. 99).

Nessa mesma direção, Bogoyavlensky e Menchinskaya (1991) afirmam que para saber como 0 conhecimento afeta o desenvolvimento "é necessário conhecer como é assimilado o material escolar, ou seja, que operações de pensamento se usam" (BOGOYAVLENSKY e MENCHINSKAYA, 1991, p. 48). No entanto, como saber como é assimilado o material escolar ou as operações de pensamento que os estudantes utilizam? A análise de como o conhecimento é projetado para ser assimilado pelos estudantes, que operações de pensamento são exigidas deles, é um caminho promissor para se alcançar essa compreensão. Pode-se analisar, portanto, como é organizado o ensino. 
Há, porém, várias formas de organizar o ensino, pois cada professor tem o seu "jeito de ensinar" e cada escola ou município tem o seu Projeto Político Pedagógico (PPP) que define encaminhamentos teórico-metodológicos próprios. Mas, para além dessas particularidades, há institucionalizado no Brasil orientações para a prática pedagógica que se materializam nos livros didáticos aprovados pelo Programa Nacional do Livro e do Material Didático (PNLD). Analisar como, no livro didático, 0 conhecimento é projetado para ser assimilado pelos estudantes, que operações de pensamento são exigidas deles, é um meio para identificar o potencial formativo do ensino ofertado. Como sugere Engeström: "[...] Num ambiente escolar, a análise crítica da prática presente poderia bem começar com um olhar rigoroso sobre os livros didáticos e currículos em áreas particulares de conteúdo" (ENGESTRÖM, 2002, p. 192).

Analisar como, no livro didático, o conhecimento é projetado para ser assimilado pelos estudantes, que operações de pensamento são exigidas deles, é um meio para identificar o potencial formativo do ensino ofertado.

\section{O MATERIAL ANALISADO E OS ELEMENTOS DE ANÁLISE}

Ao definir o modo de organização do ensino proposto em livros didáticos como objeto de análise, tendo em vista que os livros não são interdisciplinares, mas produzidos por áreas de conhecimento e por ano de escolaridade, foi necessário optar por uma área específica (Ciências) e de um ano de escolarização ( $3^{0}$ ano do Ensino Fundamental). Apesar de se eleger apenas um livro para análise, ele é tomado como expressão de um modo geral de organização do ensino. Essa organização é resultante da tradição de ensino existente, aliado aos critérios gerais que são estabelecidos pela PNLD, em consonância com a orientação curricular vigente. Razão pela qual, há mais semelhanças do que diferenças entre os livros disponibilizados pelo MEC, extrapolando, inclusive, a especificidade dos componentes curriculares.

0 critério para definição do livro a ser analisado foi 0 índice de adoção pelos municípios que compõem o Núcleo Regional de Educação de Maringá3 ${ }^{3}$ o que significa que é um material que serve de apoio para o ensino em um número significativo de escolas. De acordo com levantamento realizado por Sasaki (2017), nessa região, o livro mais adotado para o triênio com início no ano 2016 foi "Projeto Buriti: Ciências", produzido pela Editora Moderna (BAKRI, 2014). Trata-se de uma coleção que é assim avaliada pelo PNLD:

A coleção apresenta uma abordagem dos assuntos fundamentada em questionamentos e levantamento das ideias dos alunos, buscando aproximar e relacionar suas vivências com os conteúdos científicos estudados em cada unidade. A interdisciplinaridade está bem demarcada na obra e, assim, os conhecimentos da Ciência são apresentados de modo a valorizar os fatores do ambiente, da cultura, dos recursos tecnológicos e da relação com as diversas áreas de conhecimento como a Química, a Física e a Arte, por exemplo (BRASIL, 2015, p. 111).

0 livro didático "Projeto Buriti: Ciências" é organizado em nove unidades: A luz e o calor; A matéria e suas transformações; As rochas e 0 solo; $A$ água; 0 ar; As plantas; Animais vertebrados e invertebrados; 0 corpo humano por dentro; 0 esqueleto e os músculos. Todas as unidades apresentam a mesma

30 Núcleo Regional de Educação de Maringá é composto por 25 municípios. 
estrutura: No primeiro momento, é feita a abertura do conteúdo a ser estudado com imagens e algumas perguntas sobre 0 que 0 aluno já conhece do tema. Após a abertura, seguem os tópicos "Investigar 0 assunto", a apresentação do "tema" e algumas "atividades" ou experimento. Por fim, as páginas amarelas são dedicadas a reforçar o que foi ensinado na unidade, com o título "o que você aprendeu", são apresentadas atividades relacionadas a todos os temas estudados na unidade. E os tópicos seguintes são "para ler e escrever melhor" e o último é "o mundo que queremos".

Considerando que essa estrutura é comum a todas as unidades, optou-se por realizar a análise: a unidade quatro, que tem como título A água já que na singularidade dessa unidade manifesta-se a orientação geral que permeia 0 livro.

Estudos realizados por Luria (1991) e Vygotski (2014) sobre a relação entre pensamento e linguagem e, de modo específico, sobre a aprendizagem de conceitos, nos ofereceram os elementos a serem analisados na unidade. Luria (1991) evidencia que a abstração e a generalização são processos mentais que estão na base da aprendizagem conceitual. Por exemplo, quando a criança aprende que 0 recipiente que as pessoas usam para colocar líquidos para serem servidos é denominado de "jarra", normalmente, ao falar essa palavra, inicialmente vem em seu pensamento apenas a imagem específica do objeto que ela conhece. Quando, porém, a criança vê outro objeto que cumpre essa função, mas tem cor, tamanho, textura e formato diferentes e, mesmo assim, o denomina de "jarra", demonstra que abstraiu do objeto a sua característica essencial e, portanto, pode generalizar, ou seja, usar essa palavra para vários outros objetos que apresentam a mesma característica.

Na primeira situação, a palavra está restrita a um objeto específico; na segunda, representa uma generalização. Isso demonstra que verbalizar uma palavra, mesmo que de forma adequada em relação ao objeto ou fenômeno que se quer designar, nem sempre significa dominar o conceito. Então, se a palavra "jarra" está vinculada apenas à imagem mental de um objeto específico, ela está presa à referência material imediata e funcionando de modo semelhante a um nome. Mas, se a palavra é um meio para reconhecer e atuar com vários outros objetos, ela está vinculada ao significado geral, está funcionando como um conceito.

Luria (1991) afirma que "ao dominar a palavra, o homem domina automaticamente um complexo sistema de associações e relações em que um dado objeto se encontra e que se formaram na história multissecular da humanidade" (LURIA, 1991, p. 20). Ao dominar a palavra, a criança domina nexos de associações que vinculam a palavra a outras palavras, bem como à fenômenos do mundo objetivo. Esse movimento do pensamento na apropriação do significado da palavra é realizado por meio das operações de abstração e generalização. No processo de abstração são apreendidos os traços essenciais do objeto e no processo de generalização o objeto é colocado em relação a certa categoria.

Esses dois processos ocorrem na aprendizagem de todos os conceitos, portanto, estão na base de apreensão dos conceitos cotidianos e científicos. Na aprendizagem de conceitos cotidianos esse processo vai ocorrendo de modo não organizado para esse fim, se faz presente nas experiências não formais de aprendizagem. Trata-se de um processo lento, marcado por tentativas e erros. A tentativa de compreender e nomear o mundo que é intensa e criativa nos anos iniciais de vida da criança resultam, muitas vezes, em situações cômicas provocadas pelo inusitado das lógicas que as crianças usam nesse processo.

Na escola, porém, não é possível repetir esse mesmo caminho de aprendizagem. Não há como esperar que por meio do contato com vários objetos, ampliação da experiência e via tentativas e erros, a criança abstraia e generalize os significados conforme produzidos pela humanidade e sistematizados pelas diferentes ciências ao longo da história. 
No caso dos conceitos científicos, os processos de abstração e generalização precisam ser orientados, ou seja, sistematicamente organizado para conduzir ao seu domínio. Esse percurso de formação conduz não apenas à aprendizagem do conceito, mas a um modo de pensar e atuar próprio de cada ciência, denominado por Davidov (1998) de pensamento teórico. Para isso, é fundamental que os traços essenciais dos conceitos sejam devidamente explicitados nas situações de ensino, que os conceitos não sejam apresentados de modo isolado "como ervilhas em um saco", como critica Vigotski (2014), mas que as relações entre conceitos sejam evidenciadas de modo que seja formado um sistema conceitual claro. Essas duas ações de ensino (identificar os tracos essenciais e estabelecer relação entre conceitos) são condições para conduzir 0 aluno no processo de abstração. Além disso, 0 estabelecimento da relação entre os conceitos e os fenômenos da realidade é condição para 0 aluno avançar do concreto sensorial ao concreto pensado pela mediação dos conceitos científicos que foram objetos de ensino, enfim, para generalizá-los.

Com base nesses pressupostos teóricos, no ensino faz-se necessários ações que possibilitem ao estudante identificar os traços essenciais do conceito; compreender as relações entre os conceitos e estabelecer relações entre os conceitos e os fenômenos da realidade. Neste artigo, destaca-se, na análise da unidade de ensino 0 seu potencial de possibilitar ao estudante identificação dos traços essenciais do conceito. A análise foi guiada pela seguinte pergunta: os textos, imagens, tarefas propostas no livro didático auxiliam essa identificação?

\section{ANÁLISE DA UNIDADE DO LIVRO DIDÁTICO}

A unidade escolhida para análise foi a Unidade 4 - "A água". Ela segue a mesma lógica de todas as unidades: abertura do tema "A água", com imagens e perguntas sobre o que a criança já sabe do assunto. Apresenta um experimento sobre a chuva, no tópico "Investigar o assunto", com algumas perguntas sobre a atividade prática. Depois disso, tem-se a apresentação do primeiro tema à ser estudado na unidade: "A água no planeta", seguida de: "mudanças de estados físicos da água", "0 ciclo da água", "misturas na água" e por fim, "0 uso da água". Em seguida, são apresentadas algumas atividades sobre 0 que foi tratado em toda a unidade, uma atividade de pesquisa sobre o desperdício da água e no último tópico, "o mundo que queremos", propõe a discussão sobre o direito de todos a terem acesso a água potável.

Os itens em análise são referentes aos conteúdos: A água no planeta, mudanças de estados físicos da água e o ciclo da água. Esses conteúdos envolvem os conceitos de "Estados físicos da água: sólido, líquido e gasoso" e "mudanças de estados físicos da água: condensação, vaporação, solidificação, fusão". Observa-se que são conceitos interligados que formam um sistema que permite compreender vários fenômenos da realidade objetiva. Para isso, é preciso que os estudantes identifiquem os traços essenciais dos conceitos.

A unidade é iniciada com uma imagem de rio e dois tópicos de perguntas. No primeiro tópico, com o título "0 que eu vejo" foram feitas as seguintes perguntas: 1) "Onde há água na imagem?"; 2) "De que maneira a água está sendo utilizada ao longo do rio?"; 3) "Qual é a importância da água para os seres vivos da imagem?". No segundo tópico denominado "0 que eu sei", foram feitas mais algumas perguntas: 4) "Há alguma diferença entre a água do rio e a água do mar?"; 5) "Pense em seu dia a dia. Em quais atividades você utiliza água?"; 6) "Além da água líquida, em que outros estados a água pode ser encontrada?". Antes de iniciar o tema 1- "A água no planeta", o livro cita o que é a chuva e propõe às crianças que façam um experimento para entender como as chuvas acontecem. 
0 tema 1, "A água no planeta", inicia-se com o texto exposto na figura 1:

Figura 1 - A água no planeta.

\section{A água no planeta}

\section{A água na natureza}

A maior parte da superfície do planeta Terra é coberta por água.

A maioria dessa água é salgada e está nos oceanos. A água doce é encontrada em rios, lagos e geleiras. Também é encontrada no subsolo, em rochas subterrâneas que possuem pequenos espaços nos quais a água se acumula. Essas rochas são chamadas de aquíferos.

Os seres humanos e muitos outros seres vivos só consomem água doce.

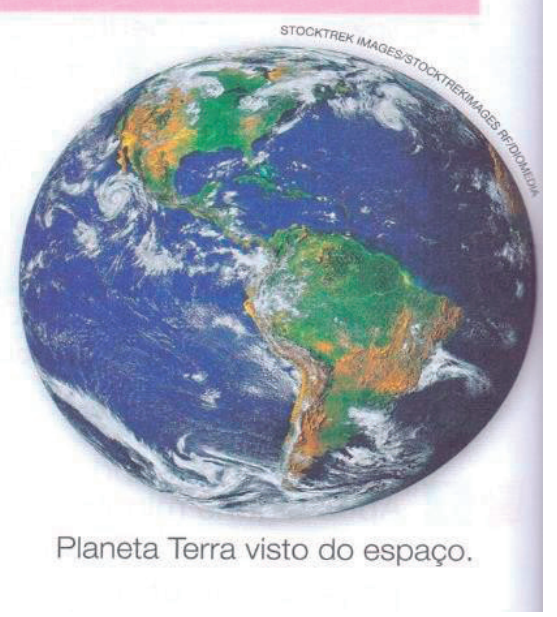

Fonte: Livro Projeto Buriti: ciências: ensino fundamental: anos iniciais - $3^{0}$ ano do Ensino Fundamental.

Observa-se que ao expor sobre a água na natureza, os autores apresentam o local que podemos encontrar água e não, exatamente, um conceito dessa substância. Em duas linhas, é explicado que os humanos e alguns outros seres vivos só consomem água doce. Ao afirmar a existência de água doce e salgada, não se faz menção da razão desses termos. Dizer que os seres humanos consomem água doce poderia ser contrastado com o fato de os alunos não beberem água, literalmente, doce, mas insípida. Essa aparente contradição poderia provocar a curiosidade dos alunos sobre 0 tema.

No texto, 0 destaque, em negrito, na palavra aquíferos, leva a imaginar que esse é 0 conceito central do texto: "Essas rochas são chamadas de aquíferos". No entanto, a imagem do globo terrestre, destaca apenas a presença de água na superfície do planeta, evidenciando a água nos oceanos.

Nesse texto inicial, a menção à água é voltada para o que é mais perceptível no cotidiano - a água em estado líquido - citando sua presença em oceanos, rios e lagos. Há apenas uma rápida menção às geleiras, que é uma manifestação particular da água em estado sólido. A presença da água em forma de vapor na atmosfera, não percebida diretamente no dia-a-dia , não é citada no texto.

Logo em seguida, são apresentados os estados físicos da água (figura 2). Sobre os estados sólido e líquido são apresentados exemplos de onde podem ser encontrados. Sobre 0 estado gasoso, não é apresentado exemplo, somente afirmado que ele é também chamado de vapor de água e que é invisível. Não há uma explicação que antecede os exemplos. A imagem apresenta um exemplo de água em estado sólido, ou seja, reforça o exemplo exposto no texto. E o gráfico traz uma informação sobre a quantidade de água doce e salgada no nosso planeta, que não tem sintonia com o que está sendo discutido no texto verbal. 
Figura 2 - Os estados físicos da água.

\section{$\rightarrow$ Os estados físicos da água}

Na natureza, a água pode ser encontrada em três estados físicos: sólido, líquido e gasoso.

- A água em estado sólido são o gelo e a neve, que se formam em lugares muito frios.

- A água em estado líquido é encontrada em rios, lagos, oceanos etc.

- A água em estado gasoso é chamada de vapor de água. O vapor de água é invisível.
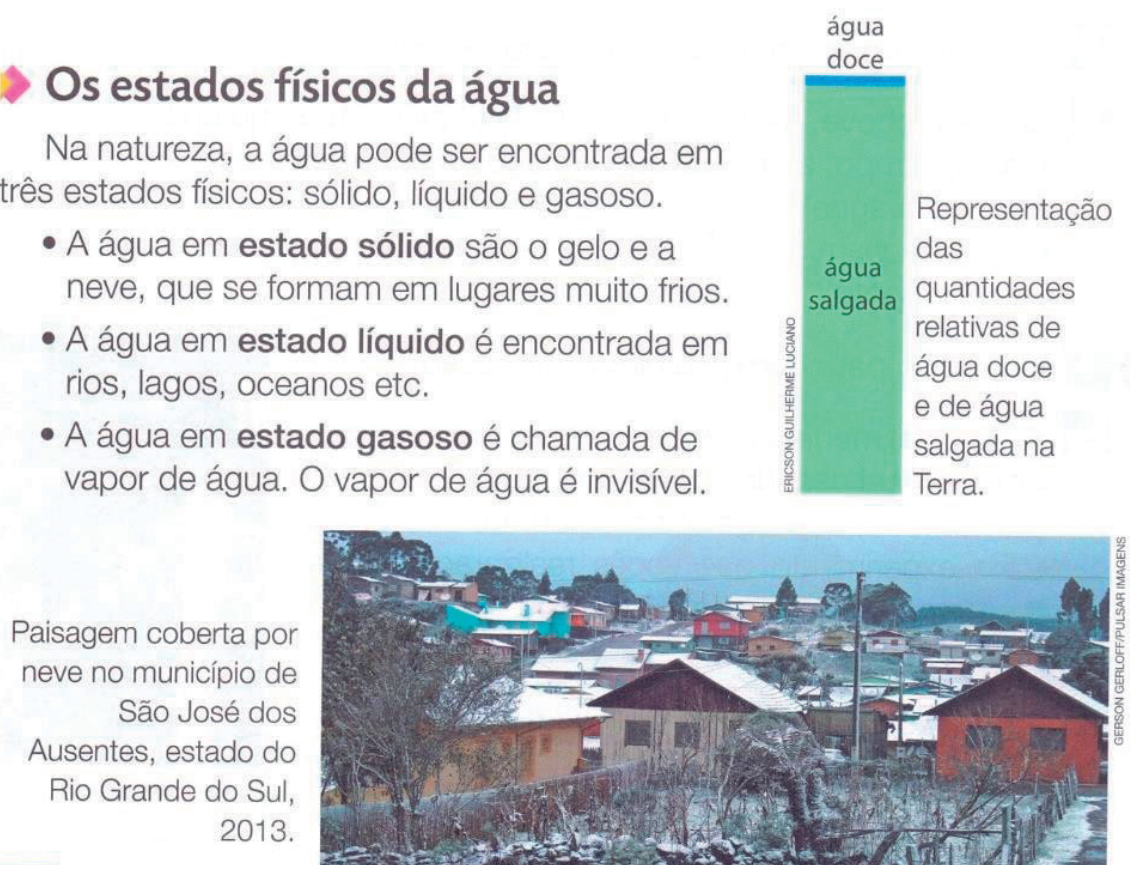

Fonte: Livro Projeto Buriti: ciências: ensino fundamental: anos iniciais - $3^{0}$ ano do Ensino Fundamental.

Apesar de ser seguidamente mencionado, em nenhum momento é explicado o que significa 0 termo "estado físico". Considerando que a palavra "estado" tem outros significados, como divisão territorial de alguns países ou conjunto de instituições que governam uma nação, certamente, as crianças já ouviram dizer que moram em determinado Estado, que uma roupa não está em bom estado, que 0 estado de saúde de alguém da família não é bom, dentre outros. A palavra "físico" também significa corpo, uma determinada profissão e o modo como algo se apresenta, provavelmente, também não é nova para as crianças. Elas fazem educação física na escola e talvez ouçam pessoas dizendo que algo exige esforço físico.

Assim, essas palavras deveriam merecer maior atenção pois o seu significado no contexto de estudo da água pode ser associado a diferentes objetos. As associações que as crianças fazem pode tanto ajudar a compreender os conceitos como criar obstáculos para a sua compreensão. Além disso, quando se afirma que serão estudados os estados físicos da água, sob quais outros aspectos a água pode ser estudada? Pode ser visto a composição química, a potabilidade, sua importância na vida humana, etc. Enfim, trata-se de um olhar para a água sob um determinado aspecto, mas esse objeto pode ser compreendido e analisado também sob outros enfoques e seria importante que a criança tivesse consciência disso.

Em seguida são apresentadas algumas tarefas aos estudantes (figura 3): 
Figura 3 - Atividades 1.

\section{ATIVIDADES}

1 Quais são os estados físicos da água? Cite um exemplo

de cada estado dela.

2 O gráfico mostra a distribuição da água no planeta Terra. Pinte as partes do gráfico de acordo com a legenda.

- Que tipo de água usamos para nosso consumo?

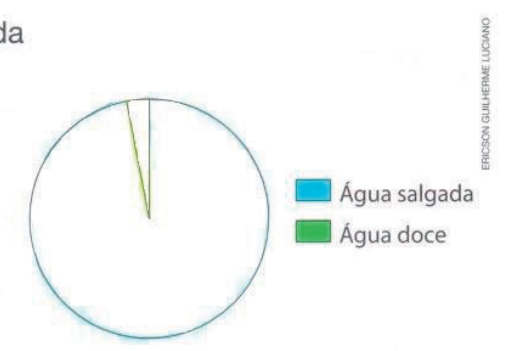

3 Leia o que a menina está pensando e responda.

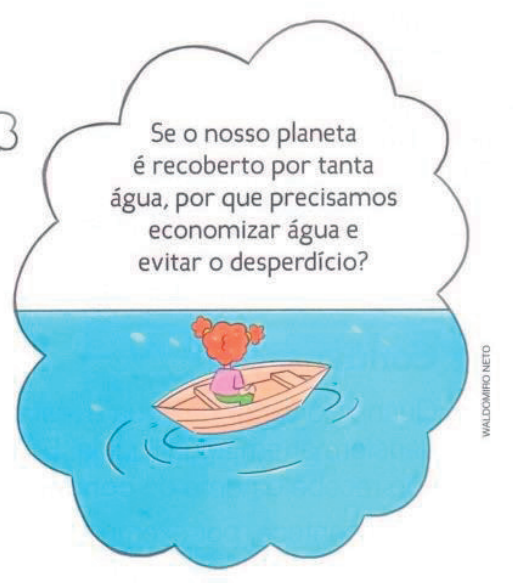

- Como você responderia a essa questão?

Fonte: Livro Projeto Buriti: ciências : ensino fundamental: anos iniciais - $3^{0}$ ano do Ensino Fundamental.

Na figura 3, a pergunta 1 exige que se repita 0 que está no texto, que seja apresentado o nome e os exemplos de cada estado físico da água. A pergunta 2 solicita que o gráfico anteriormente exposto em forma de barras seja agora pintado em forma de pizza e que seja identificado 0 tipo de água que consumimos, se doce ou salgada.

A pergunta 3 apresenta uma situação para reflexão que pode ser desafiadora para às crianças: "Se 0 nosso planeta é recoberto por tanta água, por que precisamos economizar água e evitar 0 desperdício?" (BAKRI, 2014, p. 65). Certamente, desde a educação infantil e mesmo em programas de televisão as crianças ouvem que é necessário economizar água, observando, porém, a imagem do planeta com tanta água, essa pergunta poderia levar a uma reflexão que daria sentido ao conhecimento relativo à quantidade de água salgada e doce no planeta, o tipo de água própria para 0 
consumo, bem como às tentativas e os limites da ciência em transformar a água dos oceanos para 0 consumo. 0 pequeno símbolo ao lado do número 3 , na pergunta, indica que essa atividade deve ser feita de modo oral; com isso, corre-se o risco de se limitar a uma troca de opiniões entre os alunos, encerrando-se em si mesma, sem avançar na compreensão científica sobre esse fenômeno.

Enfim, observa-se no tema 1 que o conhecimento sobre os estados físicos da água limitou-se à: a) informação sobre a existência de água no planeta, citando apenas a presença da água em estado líquido (rios, lagos e oceanos) e em estado sólido (geleiras), b) informação sobre a existência de água doce e salgada, a quantidade de cada uma delas e a relação delas com o consumo humano, c) definição de aquífero e d) exemplos sobre 0 estado sólido e líquido, e informação vaga sobre 0 estado gasoso.

A linguagem com que esses conhecimentos são passados expressam uma visão de ciência como um amontoado de informações sem vida. Parece que há um mundo parado e que nele há naturalmente nomes: "essas rochas são chamadas de.....", mas, quem as denominou assim? Por que? Como foram descobertas se não ficam visíveis na superfície do solo?; "os seres humanos e muitos outros seres vivos consomem apenas água doce" - a água que bebemos é doce? Por que as pessoas deram esse nome a ela? Por que não é possível beber água salgada? Os seres humanos já tentaram em algum momento da história beber água do oceano? E quem mora numa ilha no oceano, não bebe água salgada? E se for retirado o sal da água, não seria possível bebê-la? É possível tirar 0 sal da água do mar?; "A água pode ser encontrada em três estados: sólido, liquido e gasoso" - por que foram dados esses nomes para essas diferentes formas de apresentação da água? Quem encontrou a água em estado gasoso se nele a água é invisível? Como saber se há essa água nos lugares se não é possível vê-la?

Enfim, esses são alguns exemplos de como os fenômenos da natureza são interessantes e a produção de conhecimentos sobre eles é instigante, marcada por dúvidas, curiosidades, questionamentos e movida pela necessidade humana de compreensão dos fenômenos. Mas a linguagem com que são apresentados na escola elimina toda essa riqueza e apresenta às crianças um mundo sem vida, sem atividade humana, sem o movimento que é próprio na produção de conhecimentos.

Desse modo, a criança que na primeira infância lida com tanta criatividade com as palavras na tentativa de nomear o mundo, como exposto por Luria (1991), recebe nomes científicos "mortos". Logo, não se leva em conta essa relação inventiva e até lúdica que a criança tem com a palavra. A criança que tanto busca as razões das ações, dos objetos e fenômenos, que pergunta "por que" e "para que", na escola recebe explicações e exemplos sem que lhes sejam instigadas perguntas, curiosidades, desafios e encantamentos. Ou seja, não se aproveita o impulso infantil de desvendar o mundo, a curiosidade, o desejo de conhecer. Além de não se tomar isso como ponto de partida, a recorrente prática de um ensino desse modo, tende a levar a gradativa diminuição das perguntas e do desejo de conhecer o mundo.

Apesar de todas as questões citadas anteriomente envolverem o tema, não se pode perder de vista que elas deveriam caminhar para elucidar o que é essencial no conteúdo "estados físicos da água", ou seja, que a água é uma substância que altera a sua forma, sua apresentação na natureza, mas permanece sendo denominada de água. Mas, esse fenômeno, tão interessante do ponto de vista da ciência - os diferentes estados de uma mesma substância - não é destacado na unidade.

No tema 2, sobre as "Mudanças de estado físico da água" (figura 4), o livro apresenta pequenos textos e algumas imagens como exemplo: 
Figura 4 - Mudanças de estado físico da água.

\section{Mudanças de estado físico da água}

\section{Solidificação}

Quando a água é resfriada a temperaturas abaixo de $0^{\circ} \mathrm{C}$, ela congela, isto é, ela passa para o estado sólido. Essa mudança de estado recebe o nome de solidificação.

\section{Fusão}

Quando o gelo é aquecido e atinge temperaturas maiores do que $0^{\circ} \mathrm{C}$, ele derrete, ou seja, ele passa para o estado líquido. Essa mudança de estado é chamada de fusão.

\section{Vaporização}

A água líquida pode se transformar em vapor de água. Essa mudança de estado recebe o nome de vaporização.

Quando deixamos as roupas molhadas no varal, elas secam lentamente. A água evapora e vai para a atmosfera na forma de vapor de água.

A vaporização também pode acontecer com a formação de bolhas durante o aquecimento da água. Nesse caso, é chamada de ebulição ou fervura.

\section{Condensação}

Quando o vapor de água é resfriado, ele pode se transformar em água líquida. Essa mudança de estado recebe o nome de condensação.

Isso acontece, por exemplo, quando o vapor de água liberado durante o banho encontra a superfície fria do espelho: formam-se minúsculas gotinhas de água que deixam o espelho embaçado.

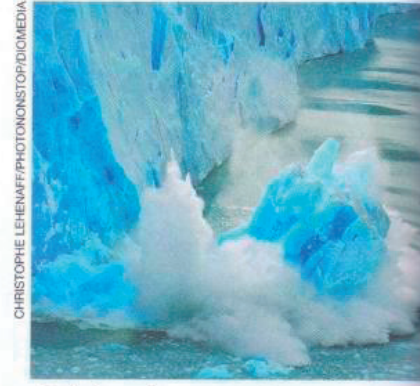

Geleira derretendo na Patagônia argentina.

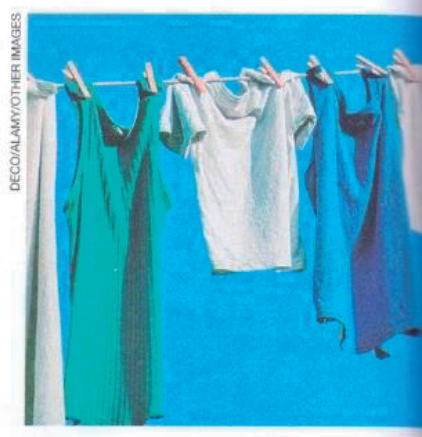

Roupas secando no varal.

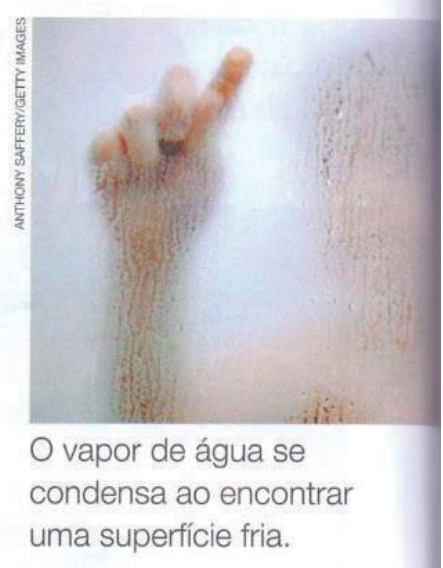

Fonte: Livro Projeto Buriti: ciências : ensino fundamental: anos iniciais - $3^{0}$ ano do Ensino Fundamental.

Esse conteúdo envolve de imediato quatro conceitos: solidificação, fusão, vaporização e condensação. Cada um desses conceitos foi apresentado via um exemplo e a definição. No caso dos conceitos de solidificação e fusão é mencionada uma certa medida de temperatura para que ocorra a mudança. No caso da vaporização não é feita menção a nenhum aspecto da temperatura. E no conceito de condensação é citado o resfriamento. As imagens apresentadas referem-se aos exemplos 
citados no texto: gelo derretendo, roupas no varal e vapor durante 0 banho. Não há imagens vinculadas ao processo de solidificação. As definições são apresentadas como "etiquetas" que aparecem nos fenômenos: "essa mudança de estado recebe o nome de solidificação"; "essa mudança de estado é chamada de fusão"; "Essa mudança de estado recebe o nome de vaporização"; "essa mudança de estado recebe o nome de condensação".

Quem deu esses nomes? É chamada assim por quê? Quando descobriram isso? Quando deram esses nomes? Por que nossos antepassados ficaram observando esses fenômenos? Essas perguntas não são feitas. A unidade segue limitando-se a destacar nomes para os fenômenos e exemplos, mostrando uma ciência sem pessoas e uma natureza isolada da atividade humana. A busca de conhecimento e de controle dos fenômenos naturais pelos seres humanos movida pela necessidade de sobrevivência, de melhores condições de vida ou de exploração econômica passa à margem do conhecimento científico apresentado.

Em seguida, são apresentadas as tarefas a serem realizadas pelos estudantes (figura 5):

Figura 5 - Atividades 2.

\section{ATIVIDADES}

1 Observe as imagens, leia as legendas e complete a tabela.

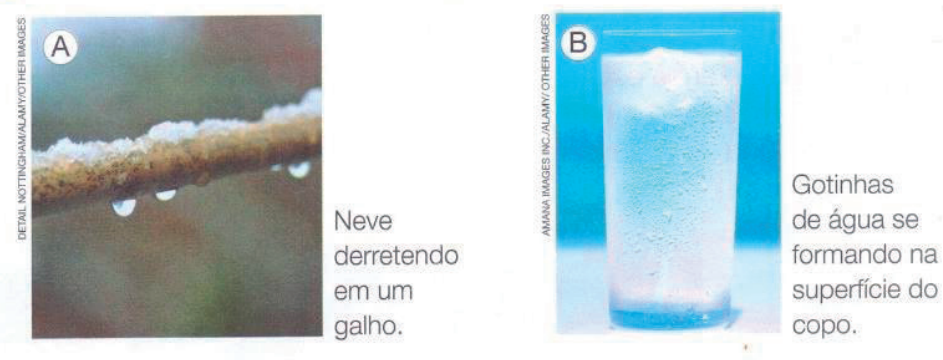

\begin{tabular}{|c|c|c|c|}
\hline Foto & A água passa do estado & para o estado & Nome da mudança \\
\hline A & & & \\
\hline B & & & \\
\hline
\end{tabular}

2 Leia o texto e responda.

O orvalho são pequenas gotas de água que se formam na superfície de objetos e plantas em madrugadas frias. Com o raiar do dia, as gotas desaparecem lentamente.

- Que mudança de estado da água ocorre na formação do orvalho? E no desaparecimento das gotas?

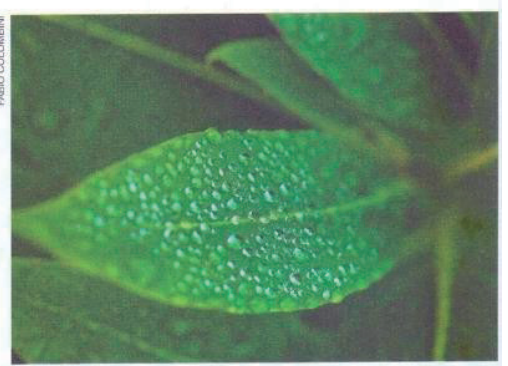

Planta coberta de orvalho.

3 Vítor preparou pão em sua casa com leite, farinha, ovos e fermento.

a) Quais ingredientes do pão caseiro contêm água?

b) $\mathrm{O}$ que acontece com o pão fresco depois de alguns dias? Você sabe por quê?

Fonte: Livro Projeto Buriti: ciências : ensino fundamental: anos iniciais - $3^{0}$ ano do Ensino Fundamental. 
Na atividade 1, na Figura 5, pede-se que 0 aluno identifique 0 estado inicial da água e 0 estado final e escreva o nome da mudança ocorrida. 0 fato de trazer outros exemplos, diferentes daqueles apresentados no texto é um ponto positivo, pois permite que 0 aluno possa associar os conceitos com um número maior de fenômenos. Mas trata-se de uma atividade que exige apenas a identificação da relação entre o fenômeno e a palavra que o denomina.

As atividades 2 e 3 devem ser realizadas apenas oralmente. A questão 2 também pode contribuir para ampliar a relação entre a palavra e os fenômenos, mas, igualmente, exige apenas 0 reconhecimento da mudança de estados da água em duas situações, na formação do orvalho e no desaparecimento dele pela manhã. Não se questiona o motivo da mudança da água.

A atividade 3, traz uma questão que provoca no aluno a percepção de que a água está inserida em outros produtos, como no leite e no ovo, não se limitando a sua presença isolada. Mas no item b é apresentada uma questão dúbia: "0 que acontece com o pão fresco depois de alguns dias? Você sabe por quê?" Pode-se dizer que o pão ficou duro que ficou com mofo. A razão para explicar que ficou duro pode ser feita pelos estudantes com base no que foi estudado, mas no caso de ter estragado, de ter surgido o bolor, não há elementos na unidade que permitam explicar esse fenômeno.

Desse modo é encerrado esse tema. Os traços essências das mudanças dos estados físicos da água - a alteração da temperatura que permite compreender as mudanças em geral e cada uma delas em particular - não são destacados nos textos, nas imagens e nas tarefas. É citada a temperatura em duas das mudanças, mas não é conferida centralidade a ela na explicação de todas. Sobre uma das mudanças há uma menção indireta à temperatura, referindo-se ao resfriamento. E sobre outra mudança, é sequer citado algo que se aproxime da ideia de que a temperatura é o fator determinante das mudanças.

Sem que 0 aspecto nuclear seja destacado, não há como abstrair as características essenciais do conceito. Assim, não se tem elementos para a compreensão das mudanças apresentadas nos exemplos, restando apenas a identificação de que houve a mudança e o nome dado a ela.

Essa abstração acerca das mudanças dos estados físicos da água é, também, condição fundamental para a compreensão do tema 3, o ciclo da água.

Por meio da imagem e quadros expostos na Figura 6, procura-se sintetizar o que foi tratado durante toda a unidade. No fenômeno "ciclo da água" estão presentes os conceitos de "estados físicos da água" e conceitos vinculados às "mudanças dos estados físicos da água".

$\mathrm{Na}$ explicação do ciclo da água pode-se identificar alguns conceitos que já foram apresentados anteriormente. No entanto, os autores não fazem menção aos termos já citados (estado sólido, estado líquido e estado gasoso, bem como solidificação, fusão, vaporização e condensação), para estabelecer conexões entre esses conceitos e 0 ciclo da água. Vygotski (2014, p. 260) afirma que "os conceitos não surgem na mente da criança como ervilhas espalhadas em um saco. Eles não se situam um ao lado do outro ou sobre o outro, fora de qualquer vínculo e sem quaisquer relações". Todavia, quando na unidade não é feita menção aos termos anteriormente citados, podemos considerar que a forma como os conceitos são apresentados pelo livro didático, isolados e sem relações entre si, pode favorecer com que fiquem "na mente da criança como ervilhas espalhadas em um saco". Os dois conceitos (estados físicos da água e mudanças dos estados físicos da água) estão vinculados a um conceito hierarquicamente superior: 0 ciclo da água. Estabelecer essas conexões entre eles permite que essas abstrações possibilitem a realização de generalizações cada vez mais teóricas, conferindo inteligibilidade para diversos fenômenos presentes na realidade objetiva. 
Figura 6 - 0 ciclo da água.

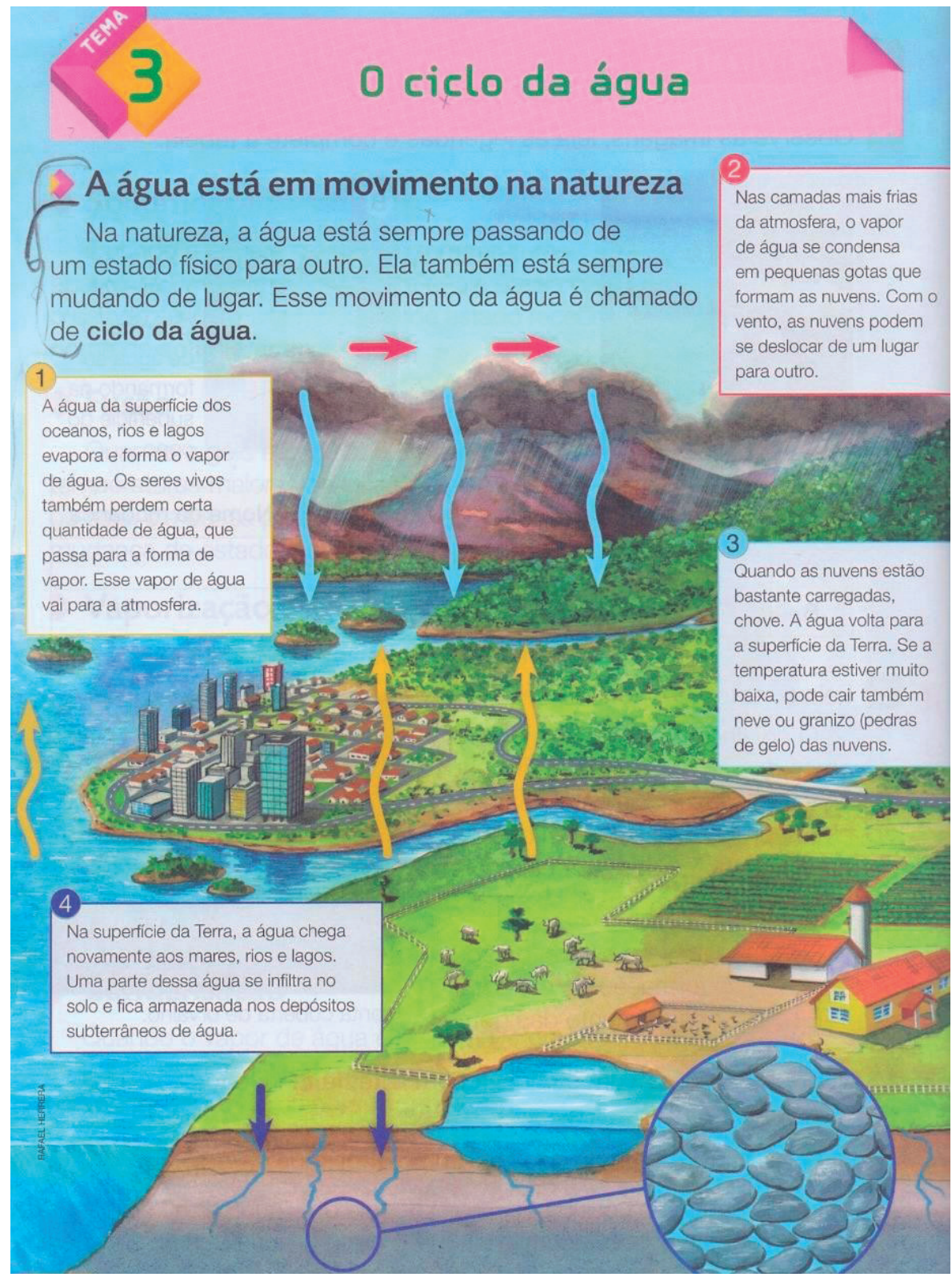

Fonte: Livro Projeto Buriti: ciências : ensino fundamental: anos iniciais - $3^{0}$ ano do Ensino Fundamental.

No quadro 1, da figura 6, não é evidenciado que o processo descrito é o de vaporização. Considerando que ao ser apresentado esse conceito no Tema 2, 0 exemplo apresentado foi 0 de roupas secando no varal, poderia estar no Tema 3 a possibilidade de ampliar a significação em formação, incluindo um fenômeno que na aparência é muito distinto (evaporação das águas dos rios, lagos e oceanos e a perda de água pelos seres vivos), mas que pode ser explicado por meio do mesmo conceito. Com essa vinculação, o que é nuclear no conceito ficaria mais ressaltado. Entretanto, essas relações não são estabelecidas e cada fenômeno tende a ser visto de modo desarticulado. 
No quadro 2, da figura 6, ocorre situação semelhante, o termo condensação não é explicitado de forma clara. Quando esse conceito foi apresentado na unidade anterior, ele foi associado ao espelho embaçado durante 0 banho, desse modo, no Tema 3 ao apresentar o processo de formação das nuvens, sem que fosse explicitado o conceito de condensação, não fica claro que se trata de outro fenômeno, na aparência bastante distinto, mas que pode ser explicado pelo mesmo conceito. 0 mesmo ocorre nos textos presentes nos quadros 3 e 4 da figura 6 .

Esse modo de condução do ensino não deixa explícito nem um processo indutivo de formação de conceitos (dos fenômenos particulares para o conceito), nem um processo dedutivo (do conceito para os fenômenos particulares). Os traços essenciais do conceito não são explicitados, o que dificulta chegar à abstração necessária para a realização do movimento particular-geral e geral-particular. Espera-se que essa relação seja estabelecida pelo aluno, mas as tarefas propostas não favorecem 0 estabelecimento dessas relações.

Após o texto explicativo "0 ciclo da água" seguem-se as "atividades" expostas na Figura 7.

Figura 7 - Atividades 3.

\section{ATIVIDADES}

Observe as figuras e preencha os quadros com os números correspondentes.
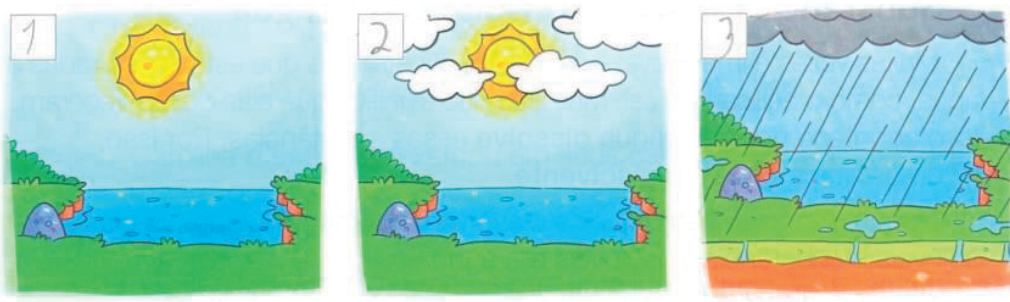

1. Quando as nuvens estão bem carregadas, chove.

2. A água que evapora dos oceanos, rios e lagos e a água que os seres vivos perdem formam o vapor de água que vai para a atmosfera.

3. Na atmosfera, o vapor de água se condensa, formando as nuvens.

Leia o texto, observe a imagem e responda.

Amanda vai tomar uma xícara de chá. Para o chá não esfriar, ela cobriu a xícara com um pires.

a) $O$ que vai se formar na superfície do pires voltada para a xícara? Explique.

b) Qual é o nome da mudança de estado que ocorreu?

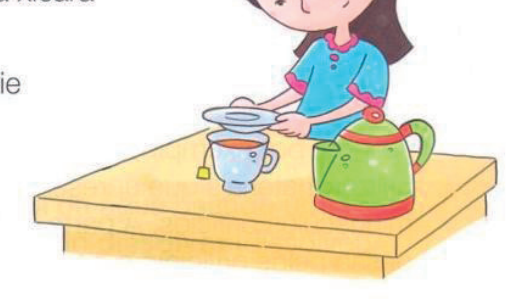
$\checkmark A P O R O$

Você já observou as nuvens se movendo no céu? É correto dizer que a água é transportada pelas nuvens de um lugar para outro?

Fonte: Livro Projeto Buriti: ciências : ensino fundamental: anos iniciais - $3^{0}$ ano do Ensino Fundamental. 
Na figura 7, na atividade 1, temos uma sequência de imagens e três enunciados escritos, cada enunciado corresponde a uma imagem. Nessa atividade, não é necessário que a criança entenda 0 ciclo da água para que enumere adequadamente as imagens. A frase 1 "quando as nuvens estão bem carregadas, chove" além de ser facilmente associada ao único quadro que contem ilustração de chuva, exige apenas um conhecimento advindo do cotidiano. Antes de chegar à escola, certamente, a criança já associou a presença de nuvens com a chuva, pessoas sem escolarização também fazem isso sem qualquer dificuldade, portanto, esse não é 0 conteúdo escolar propriamente dito. A relação entre nuvem e chuva constitui-se apenas no ponto de partida para que, via aprendizagem dos conceitos científicos, essa relação seja compreendida e não apenas constatada.

No enunciado 2 observa-se a dificuldade de expressar um conceito científico por meio de imagens, por meio da representação material direta. Considerando que o conceito que se deseja ilustrar é evaporação e essa é uma transformação física cujas mudanças ocorrem em nível molecular, dificilmente esse conceito pode ser entendido recorrendo-se à percepção visual direta. Portanto, uma imagem de um rio e o sol são pouco reveladores do que é nuclear no conceito de evaporação. Se cada palavra envolve a representação material e 0 significado abstrato e generalizador (LURIA, 1991), pode-se reconhecer que em conceitos como cadeira, gato, casa, etc., que são assimilados no cotidiano, as relações direto-figuradas predominam. Já, como afirma Luria, "É inteiramente distinto o que ocorre com os conceitos científicos" (LURIA, 1991, p. 39), neles predominam as operações lógico-verbais, ou seja, seu significado abstrato e generalizador e não as relações direto-figuradas. Com outras palavras, Vygotski (2014) tece essas mesmas considerações, afirmando que conceitos científicos e cotidianos apesar de se interrelacionarem, seguem caminhos opostos: se na aprendizagem de conceitos cotidianos, "a criança vai da coisa ao conceito", na aprendizagem de conceitos científicos "se vê obrigada com frequencia a seguir o caminho oposto: do conceito ao objeto" (VYGOTSKI, 2014, p. 253).

Quando, na unidade analisada, verifica-se a intenção de expressar o conceito de evaporação apenas com imagens, observa-se que nela é usado o procedimento de aprendizagem de conceitos cotidianos para explicar conceitos científicos, ou seja, do objeto ao conceito, o que não contribui para a apropriação do significado abstrato e generalizador presente na palavra. Nesse modo de exposição, a criança tende a relacionar o conceito apenas à ilustração - que, neste caso, não evidencia o fenômeno por ele ocorrer em níveis moleculares - predominando, assim, a representação material, desvinculada do significado abstrato e generalizador, que é essencial na aprendizagem de conceitos científicos.

0 enunciado 3 também apresenta essa mesma característica, no entanto, certamente, será mais facilmente respondido por constar nele a palavra "nuvens" que podem ser prontamente identificadas na imagem. No entanto, a resposta correta pode representar apenas a associação entre a palavra nuvem e a imagem de nuvem, sem que esteja presente no aluno qualquer relação do fenômeno com 0 conceito de condensação.

A atividade 2 é composta por situação problema semelhante ao experimento da chuva proposto no início da unidade. Os fenômenos são diferentes, mas podem ser explicados pela mediação dos mesmos conceitos. "Amanda vai tomar um xícara de chá. Para o chá não esfriar, ela cobriu a xícara com um pires. A) 0 que vai se formar na superfície do pires voltada para a xícara? Explique. B) Qual é o nome da mudança de estado que ocorreu?" (BAKRI, 2014, p. 69). Observa-se que ao lado do texto verbal há um símbolo, ele indica que essa atividade deve ser feita coletivamente. Ela pode se constituir em uma atividade mobilizadora do pensamento dos estudantes, já que exige a explicação de 
um fenômeno pela mediação do conceito. Se os alunos se apropriaram do conceito de vaporização e condensação podem explicar a presença desses processos no fenômeno específico apresentado.

No entanto, os estudantes podem também ficar restritos ao relato empírico do que imaginam que vai acontecer ("vai formar gotículas de água no fundo do pires", "0 fundo do pires ficará molhado", etc) e não explicarem conceitualmente a transformação física que ocorrerá. Observa-se que ao solicitar que 0 aluno responda "qual é o nome da mudança de estado que ocorreu", a preocupação está na designação verbal do fenômeno, e não na sua compreensão como mediador, como instrumento simbólico que permite explicar o que é exposto na questão "a".

A última atividade, a questão 3, "você já observou as nuvens se movendo no céu? É correto dizer que a água é transportada pelas nuvens de um lugar para outro?" (BAKRI, 2014, p. 69) faz com que a atenção dos alunos volte-se para a relação entre a nuvem e a presença de água nelas, bem como 0 deslocamento dessa água por meio do movimento das nuvens, provocado pelo vento. Questionamentos que, tal como na questão anterior, podem ser respondidos pela percepção imediata, sem relação com o conhecimento científico.

Ao ser acompanhado o desenvolvimento dos três temas procurando analisar se os textos e atividades propostas favorecem a identificação dos traços essenciais dos conceitos, já que essa identificação é fundamental no processo de abstração, percebe-se que cada conceito é rapidamente associado a um fenômeno singular, via exemplos. Ao serem oferecidos novos exemplos para os conceitos em temas subsequentes, não se faz a relação com o que foi exposto anteriormente, o que poderia favorecer a identificação pelo aluno do que é essencial no conceito e o que é próprio da situação particular apresentada. Como o processo de abstração precisa ser orientado para que em meio a textos e imagens seja ressaltado o conceito e 0 sistema de conceitos, a ausência de orientação nesse sentido, pode comprometer o processo de abstração dos conceitos científicos, afetando também 0 processo de generalização, impossibilitando o desenvolvimento, no estudante, de um pensamento orientado pela ciência ensinada.

\section{CONSIDERAÇÕES FINAIS}

Esta pesquisa foi instigadas pelo fato de haver na Teoria Histórico-Cultural a valorização da aprendizagem de conceitos científicos como fundamental para o desenvolvimento do pensamento teórico e de uma concepção de mundo mais sistêmica e profunda nos estudantes e, nem sempre, se observar mudanças significativas em argumentos apresentados por pessoas escolarizadas acerca de fenômenos que, na atualidade, têm mobilizado o debate público em diferentes espaços, inclusive, nas redes sociais.

Considerando que as ações intelectuais, antes de serem internas, intrapsíquicas, são externas, promovidas nas interações inter-psíquicas ${ }^{4}$, ou seja, que "por detrás de todas as funções superiores e suas relações se encontram geneticamente as relações sociais", (VYGOTSKI, 2012, p. 150), analisar nessas interações, que ocorrem no plano social, como é compartilhado o conhecimento científico e as operações de pensamento que são requeridas dos estudantes, pode ajudar a entender as razões dessa distância entre 0 anunciado teoricamente e a formação propiciada.

\footnotetext{
4 "Podemos formular a lei genérica geral do desenvolvimento cultural da seguinte maneira: cada função no desenvolvimento cultura da criança aparece em cena duas vezes, em dois planos; primeiro no plano social e depois no plano psicológico, primeiro entre os homens como uma categoria interpsíquica e então dentro da criança como uma categoria intrapsíquica. 0 que foi dito refere-se igualmente à atenção, memória voluntária, lógica, formação de conceitos e desenvolvimento da vontade. Temos todo o direito de considerar a tese exposta como uma lei, mas a passagem, naturalmente, do externo ao interno, modifica o próprio processo, transforma sua estrutura e funções. Por detrás de todas as funções superiores e suas relações se encontram geneticamente as relações sociais, as autenticas relações humanas" (VYGOTSKI, 2012, p. 150).
} 
Desse modo, o objetivo da investigação foi o de identificar a forma de organização do ensino de conceitos apresentada no livro didático e analisar o seu potencial de promover 0 desenvolvimento psíquico dos estudantes. Para isso, observou-se como o conhecimento é projetado para ser assimilado pelos estudantes, quais operações de pensamentos são exigidas deles. 0 interesse era saber como é 0 modo usual de organização do ensino de conceitos, o que ele exige e proporciona aos estudantes.

Tem-se clareza de que o livro didático é um material cuja forma de uso varia entre os professores, ele pode ser o material que define, integralmente, o conteúdo e a metodologia seguida pelo professor ou pode ser apenas um apoio para a organização da atividade de ensino. No entanto, mesmo quando não utilizado na íntegra, ele exerce influência sobre as ações de ensino, já que, muitas vezes, constitui-se no único material de consulta, pelos professores, para a preparação de aulas. Desse modo, o livro didático mantem-se como referência, mesmo quando não está presente fisicamente na sala de aula. 0 que 0 torna um rico material para análise.

Nesse material, de forma explicita ou implícita, está objetivada uma organização do ensino apoiada em concepções do que é o conceito e o que é aprender conceitos. A linguagem utilizada e 0 tipo de tarefas propostas são uma espécie de modelo de ensino que está presente na tradição escolar, sendo naturalizado como "a forma de ensinar e aprender".

Estudos sobre formação de conceitos na criança apresentados por Luria (1991) elucidaram a relação e a distinção entre 0 significado da palavra e a sua referência material, ou seja, seu significado abstrato e generalizador e a sua representação material. Essa relação vai se complexificando à medida que os significados se tornam mais abstratos, como ocorre com os conceitos científicos, que são mais abstratos e genéricos e abrangem representações materiais que nem sempre podem ser captadas sensorialmente. Devido a essa complexidade, os conceitos científicos, em seus sistemas conceituais, mereceram atenção de Vygotski (2014) ao estudar o papel da aprendizagem desse tipo de conceito no desenvolvimento psíquico dos sujeitos. Diferentemente dos conceitos cotidianos, para serem apropriados, os conceitos sistematizados que compoem o corpo das diferentes ciências, exigem intervenções dirigidas e intencionais.

Nas ações de ensino, é fundamental que os traços essenciais dos conceitos sejam explicitados e que a relação entre conceitos seja destacada como um sistema articulado, de modo que se forme a abstração do conteúdo ensinado. Também, considerando que o conceito é um instrumento simbólico, nas ações de ensino o seu papel como elemento que permite compreender a realidade, deve estar presente. Ou seja, no ensino é necessário contemplar a relação do conceito com os fenômenos da realidade que podem ser compreendidos por meio dele, propiciando, assim, condições para a generalização.

Essas ações de ensino que requerem operações de pensamento na aprendizagem conceitual, foram tomadas como elementos de análise de uma unidade de ensino do livro didático. Neste artigo, destacou-se a análise acerca da identificação dos traços essenciais dos conceitos.

Por meio da análise do livro didático identificou-se que na forma de ensinar conceitos permanece a tendência nominalista e associacionista (SFORNI, 2003). Ao longo da unidade analisada observa-se a preocupação em introduzir um conceito, defini-lo verbalmente e apresentar um exemplo que 0 ilustra. Os conceitos são apresentados de modo fixo, isolado e "morto", isto é, sem vinculação com a atividade humana que the deu origem e na qual se faz presente na atualidade. As operações de pensamento exigidas dos estudantes resumem-se a identificação da relação entre o "nome" e uma representação material. Preso a esse procedimento de exposição de cada palavra-termo, os traços essenciais dos conceitos não são destacados. 
Além disso, apesar da extrema vinculação entre os conceitos apresentados em cada tópico da unidade, essa vinculação não é ressaltada, parecendo se tratar de um conteúdo novo a cada tópico, não sendo articulados os conceitos em um sistema explicativo.

Os fenômenos da realidade apresentados aparecem apenas como exemplos do conceito ensinado, não como situações que podem ser entendidas pela mediação do conceito científico. Ou seja, não se evidencia os processos de abstração e generalização que estão na base da aprendizagem conceitual, desse modo, os conceitos ensinados tendem a não modificar o pensamento do estudante sobre a realidade.

Conclui-se que o modo usual de organização do ensino expresso no material didático analisado, não exige ações que levem os estudantes a "pensarem com" o conceito, e que está, nesse aspecto, a raiz da diferença entre as afirmações teóricas positivas sobre a aprendizagem conceitual e a realidade atual que parece negar esse potencial formativo da aprendizagem de conceitos científicos.

A constatação desse fato permite considerar que numa escola comprometida com o desenvolvimento psíquico dos estudantes é preciso não apenas à presença de conceitos científicos em sala de aula, mas empreender esforço na superação da tendência nominalista e associassionista que marca a prática pedagógica. Essa superação ocorre por meio da compreensão do conceito como instrumento mediador do pensamento humano, o que implica outra forma de organizar o seu ensino (SFORNI, 2015). Trata-se de uma tarefa que precisa ser assumida coletivamente por professores e pesquisadores que vêem na escola um locus de construção de resistência ao esvaziamento não apenas do conteúdo escolar, mas também, e por decorrência, do conteúdo do debate acerca dos importantes temas que tem ocorrido na esfera pública.

\section{REFERÊNCIAS}

BAKRI, Maissa Salah. Projeto Buriti: ciências: ensino fundamental: anos iniciais / organizadora Editora Moderna; 3. ed. São Pauo: Moderna, 2014.

BOGOYAVLENSKY, D. N., MENCHINSKAYA, N. A Relação entre aprendizagem e desenvolvimento psicointelectual da criança em idade escolar. In: LURIA, A. R. at al. Psicologia e Pedagogia I: bases psicológicas da aprendizagem e do desenvolvimento. Tradução: Rubens Eduardo Frias. São Paulo: Editora Moraes, 1991.

BRASIL. Guia de livros didáticos: PNLD 2016: Ciências: ensino fundamental anos iniciais. Brasília: Ministério da Educação, Secretária de Educação Básica, 2015.

DAVÍDOV, V. V. La enseñanza escolar y el desarrollo psíquico. Moscú: Editorial Progreso, 1988.

ENGESTRÖM, Y. Como superar a encapsulação da aprendizagem escolar. In: DANIELS, H. Uma introdução a Vygotsky. São Paulo: Loyola, 2002. p. 175-198.

LURIA, A. R. Curso de Psicologia geral. Rio de Janeiro: Civilização Brasileira, 1991, v. IV.

SASAKI, A. H. Relações entre proposta curricular, Teoria Histórico-Cultural e ensino: um olhar para os livros didáticos do ensino fundamental I. Trabalho de Conclusão de Curso (Graduação em Pedagogia) - Universidade Estadual de Maringá, Maringá, 2017. 
SFORNI, Marta Sueli de Faria. Aprendizagem conceitual e organização do ensino: contribuições da teoria da atividade. Araraquara: Junqueira \& Marin Editora, 2004.

SFORNI, Marta Sueli de Faria. Interação entre Didática e Teoria Histórico-Cultural. Educação \& Realidade, Porto Alegre, v. 40, n. 2, p. 375-397, jun. 2015. Disponível em: https://bit.ly/2ZlutRA. Acesso em: 28 jul. 2019.

VYGTOSKI, L. S. Obras escogidas. Tomo III. Madrid: Machado Libros, 2012.

VYGOTSKI, L. S. Obras escogidas. Tomo II. Madrid: Machado Libros, 2014.

RECEBIDO EM: 13 mai. 2021

CONCLUÍDO EM: 28 ago. 2021 
